This is the peer reviewed version of the following article: O'Dwyer, Emma (2020) Reading the public : political action and its relationship to constructions of political disagreement and opinion climate in the context of Brexit. Political Psychology, 41(5), pp. 945-960., which has been published in final form at https://doi.org/10.1111/pops.12658.

This article may be used for non-commercial purposes in accordance with Wiley Terms and Conditions for Use of Self-Archived Versions 


\title{
Reading the public: Political action and its relationship to constructions of political disagreement and opinion climate in the context of Brexit
}

\begin{abstract}
Keywords: political behaviour, political disagreement, opinion climate, public opinion, metarepresentations, Brexit, collective action, social representations
\end{abstract}

\begin{abstract}
This study applied a social representations approach to investigate the ways in which constructions of perceived political disagreement and the prevailing opinion climate were implicated in people's construals of political participation in the context of the United Kingdom European Union referendum of 2016. Interviews were conducted with 19 residents of the United Kingdom who voted to remain in the referendum, located in constituencies which represented diverse opinion climates in relation to the referendum. Thematic analysis of the data revealed a social representation of public opinion characterised by ambivalence; it was inscrutable and often ill-informed but also volatile and disruptive, which left open the possibility of it moving towards a more pro-EU position. Furthermore, constructions of a polarised and dysfunctional political system worked to sustain a mode of political engagement which prioritised and positioned as efficacious individual rather than collective anti-Brexit political behaviour. These findings are discussed in relation to their implications for understandings of support for forms of democratic governance as well as previous work linking meta-representations to political behaviour and expression.
\end{abstract}

\section{Word count: 8,974}


Much research within political psychology and political science has addressed the way in which perceptions of public opinion, particularly political disagreement and readings of the prevailing opinion climate, shape people's political expression and participation, with some studies suggesting that these experiences have a 'dampening effect' in particular contexts (e.g. Glynn, Hayes, \& Shanahan, 1997; Noelle-Neumann, 1974). However, other studies have found that perceptions of political disagreement or a hostile opinion climate might instead motivate people to engage politically in certain situations (e.g. Louis, Duck, Terry, \& Lalonde, 2010), or to moderate their political engagement in some way (e.g. Vraga, Thorson, Kligler-Vilenchik, \& Gee, 2015).

Perceptions of political disagreement and of the prevailing opinion climate can both be considered as components of the meta-representational fabric of a society; they refer to judgments, conscious or not, of the 'sharedness' of one's opinions and the way in which these might be received by others. A social representations approach (SRA) highlights the importance of these meta-representations (e.g. Elcheroth, Doise, \& Reicher, 2011; O’Dwyer, Lyons, \& Cohrs, 2016) for accounts and explanations of political behaviour and opinion, but, importantly, acknowledges that these meta-representations are changeable, contextdependent, and mediated (Portelinha \& Elcheroth, 2016). Furthermore, according to a SRA, they are constructed, which necessarily means that they can be reconstructed to enable and empower, rather than silence. Adopting this theoretical lens, the current study investigates the relationship between perceptions of political disagreement and opinion climate, and constructions of political participation and engagement in the context of the 'emergent form' (Andreouli, Kaposi, \& Stenner, 2019) of the 2016 United Kingdom (UK) referendum vote to leave the European Union (EU).

\section{The Influence of Perceptions of Public Opinion on Political Behaviour and Expression}


The way in which public opinion is perceived (or misperceived) impacts on an individual's willingness to engage politically, for example, to speak out about controversial or moral issues. Public opinion is defined here as "opinions on controversial issues that one can express in public without isolating oneself" (Noelle-Neumann, 1984, pp. 62-63). This links to a conceptualisation of public opinion as social control, distinct from its conception as rationality enacted in the public sphere. A consideration of public opinion as social control, as a means through which societies facilitate social cohesion through consensus, differs from the rational model in three key ways (Scheufele \& Moy, 2000). Unlike the rational model, the social control model conceptualises public opinion as (1) working through non-verbal and visual material (e.g. banners), as well as reasoned debate and discussion; (2) mostly unconscious and not dependent on motivation or ability; and (3) involving all in society, not just an informed and motivated sub-set of the population.

Research has examined the ways in which perceptions of public opinion, broadly defined in line with the social control model above, affect political behaviour and expression. For example, studies have examined the consequences of experiencing political disagreement, or occupying an opinion climate which legitimises opposing values or beliefs, for political behaviour and expression. Political disagreement may have a dampening effect on these behaviours, through the stimulation of attitudinal ambivalence and conflict avoidance tendencies (Mutz, 2002). Relatedly, those who hold minority opinions may express their attitudes more slowly than those whose views correspond to those of the majority - the minority slowness effect. Using correlational data from five studies with Canadian students and non-students, minority opinions on a range of issues were expressed more slowly than majority opinions, and this difference in response latency was related to the difference in size between the minority and majority (Bassili, 2003). In addition, this difference in response 
latency was largest for participants who had more accurate estimates of majority and minority support among their fellow university students.

The effect of perceived political disagreement on political behaviour and expression has also been investigated in relation to social networks such as Facebook. A mixed-methods study with young people in the United States of America explored their views about political discussion on Facebook (Vraga et al., 2015). Qualitative analysis revealed negative perceptions of political discussion on Facebook, which shaped political engagement on this website, by motivating them to avoid it completely or focus on uncontroversial issues, for example. Survey data showed that the effect of perceived political disagreement on the belief that Facebook was an appropriate place to discuss politics was moderated by conflict avoidance, while its effect on willingness to post political content was moderated by both conflict avoidance and political interest. Other studies which have investigated the effect of perceived disagreement on political behaviours have pointed to additional moderators, such as generalised social trust (Matthes, 2012) and the extent of political disagreement (Nir, 2011). Importantly, whether political disagreement is perceived as demobilising is also dependent on whether the opinion held is a minority or majority view (McClurg, 2006).

Spiral of silence theory (e.g. Noelle-Neumann, 1974; Noelle-Neumann \& Petersen, 2004) also specifies the importance of perceptions of public opinion on political expression and behaviour. At the most basic level, this theory posits that an individual's perception of the opinion climate, particularly the extent to which their view is shared, will affect their willingness to speak out. As these perceptions are taken from cues in the social environment, for example in the media (where there may be vocal or highly salient actors), people may have biased interpretations of the majority/minority status of their beliefs. Additionally, people are responsive to changes in the opinion climate, such that if they perceive their views as growing in popularity, they will be more likely to speak out. The reverse will take place if 
they perceive their views to be on a downward trajectory. A meta-analysis found a small significant positive correlation between perceived support for opinion and willingness to speak out (Glynn et al., 1997). However, Bodor (2012) critiqued the "microscopic approach" (p. 273) taken to a complex multilevel theory in previous empirical tests, and pointed to two key factors which might explain the lack of support found for the theory. Firstly, the operationalisation of the independent variable in terms of perceived opinion congruity fails to recognise that gauging the opinion climate is often an unconscious process. Secondly, the failure to identify the spiral of silence in previous work might plausibly be explained by the timing of data collection, as the silence hypothesis should only be supported at a particular point in the process specified in Noelle-Neumann's theory. Similarly, Scheufle and Moy (2000) pointed to problems with operationalisation (i.e. of the dependent variable, speaking out), and the failure to account for important macro-level variables (e.g. examining cultural differences, media influences), in spiral of silence research.

There may also be other factors which determine whether a hostile opinion climate brings about a 'dampening effect' on political behaviour and expression. Across three survey studies with Swiss participants in relation to a number of moral issues, the effect of opinion climate (majority/minority) on political expression was moderated by attitude extremity (Matthes, Rios Morrison, \& Schemer, 2010). For people who were high in attitude certainty, there was no relationship between opinion climate and political expression, while for those of low or moderate attitude certainty, opinion climate negatively affected political expression.

Conversely, the perception that one's views are being silenced may instead motivate people to speak out (Louis et al., 2010). Among white Australian supporters of a new conservative political movement, willingness to speak out about the issue of Asian immigration and get involved in the political debate was predicted by the perceived threat of Asian immigration to White Australians and the perception that most Australians were also 
opposed to Asian immigration. However, for opponents of this movement, the perception that public opinion was becoming more opposed to Asian immigration, as well as higher education and positive personal opinions towards Asian immigration, positively predicted their willingness to speak out about the issue and get involved in the political debate.

Most of the research which has explored the effect of perceived political disagreement and construals of the opinion climate in relation to political behaviour and expression has used quantitative methods. Therefore, little is known about the ways in which people construct public opinion, or the way in which these constructions are implicated in political participation and opinion. Furthermore, I argue that this research has tended to downplay the changeable, mediated, and context-dependent nature of relevant constructs, such as opinion climate. Additionally, the research does not give enough credence to individual agency, to resist or recast norms, beliefs, and opinions which constitute the social normative context. To address these concerns, I adopted a SRA (e.g. Moscovici, 1961/76; Elcheroth et al., 2011) in this study.

\section{Meta-Representations, Political Behaviour, and the Public}

Work utilising a SRA is concerned often with the content of common sense and the processes which give rise to it (e.g. Moscovici, 1961/76). This stock of lay knowledge is underpinned by a "dialectic of cooperation and conflict" (Howarth, 2006, p. 71): social representations are characterised by their argumentative nature, their contradictions and ambivalence, as much as by consensus.

Two related strands of research within the SRA have relevance to the aims of the current study. Firstly, a recent line of work has emphasised the importance of metarepresentations, as 'world-making assumptions' (Elcheroth et al., 2011) for understandings of social change and has investigated their impact in relation to political behaviour and 
opinion. Meta-representations are "perceptions of what most others value or reject...along with beliefs regarding what relevant others know, think or intend to do more generally" (Portelinha \& Elcheroth, 2016, p. 662). Staerklé, Clémence and Spini (2011) assert the importance of intergroup boundaries and intragroup contestation and debate for the impact of meta-representational processes on the construction of political knowledge. Metarepresentations thus encompass perceived political disagreement and readings of the opinion climate; however, the SRA differs from the research reviewed above through its conceptualisation of the social normative context as dynamic, context-dependent, and mediated, as well as influential for behaviour and contingent on social identity processes (Portelinha \& Elcheroth, 2016).

Three recent studies have applied this lens to political behaviour and opinion. A longitudinal and experimental study conducted at a traditionally left-wing Parisian university, found that when students were told that the majority of French students were positive about the far-right National Front party, they were less willing to voice their opposition towards the party by signing up to participate in a workshop to discuss its politics (Portelinha $\&$ Elcheroth, 2016). Similarly, when Swiss students who identified strongly with their university, which was known for its opposition to the right-wing populist party (the Swiss People's Party, SPP), read material which emphasised the traditional ideological differences between the university's social science students and the SPP, they were less likely to volunteer for a follow-up focus group to discuss a vote proposed by the SPP (GoncalvesPortelinha, Staerklé, \& Elcheroth, 2017). Finally, an analysis of focus group discussions with Irish citizens about foreign policy (O’Dwyer et al., 2016) demonstrated that younger Irish citizens' awareness of and orientation towards the policy stance of neutrality as widely understood as hypocritical and partial opened up a space for these participants to argue for alternative foreign policy positions. This implies that meta-representations have the capacity 
to enable and empower, as well as silence and demobilise, as they can provide the impetus and discursive resources, for the advancement of alternative representations and thus social and political change.

A second strand of research with relevance to the aims of the current study concerns the public sphere and public narratives. The public sphere as a place of 'otherness', distinct from the familial and the private is a historical artefact linked to the growth of indoor spaces, the preserve of the patriarchal family, and it is this development which sets up a contrast between the private, indoor spaces of subjectivity and relationships, and the public arena 'out there' of citizenship and debate (Jovchelovitch, 1995). Social representations are inextricably linked to the public sphere - their contents are shaped by its interactions, the media, and the other various communicative practices which constitute it (Jovchelovitch, 1995). They are elaborated relationally, in conversation with the public sphere: "agentic sense making... is shaped by existing and imagined conversations relating both to prosaic matters and the wider political conversations that circulate" (Mahendran, Jackson, \& Kapoor, 2015, p. 147).

Illustrating this, empirical work examining EU citizens' engagement with public narratives on the European Union, European citizenship, mobility and migration, showed a process of authoring, in which people integrated and spoke to the arguments of others to elaborate their positions (e.g. Mahendran, 2017; Mahendran et al., 2015). Mahendran (2018) further described six positions taken by EU citizens when generalising the public in talk about EU integration. Participants often moved between these oppositional and nonoppositional positions, which differed in terms of where how the public was positioned temporally, spatially, and relationally. This understanding of the 'dialogical citizen' developed here, along with work on meta-representations reviewed above, affords us with a view of the political subject as agentic and constantly in conversation with the opinions and narratives which characterise the public sphere. 


\section{'Brexit': The Political Context and Current Research}

In the referendum of the 23rd June 2016, a majority (52\%) of voters in the United Kingdom (UK) voted to leave the European Union (EU). Since that date, the 'Brexit' issue has dominated political discourse in the UK, and political developments have been unpredictable and constant. In spite of this difficulty, I will provide a brief outline of some of the key events here to contextualise the study.

Following almost a year of negotiations with the EU, in June 2017, a general election delivered a hung parliament, contrary to predictions of a Conservative party majority win. Without a majority, the Conservative Prime Minister Theresa May subsequently negotiated a minority government by way of a 'confidence and supply' voting arrangement with the Northern Ireland Democratic Unionist Party. May negotiated a withdrawal agreement with the EU and sought two extensions to the UK's leaving date in order to find the necessary parliamentary support for it. Unable to do so, and in the aftermath of a poor Conservative party performance in the European Parliament elections, she resigned as Prime Minister in June 2019. At the time of writing, the UK is set to leave the EU on the 31 st October 2019 under the direction of the new Conservative Prime Minister, Boris Johnson. The possibility remains that this will take place even in the absence of agreeing the terms of the UK's departure with the EU, and a further general election looks imminent.

A growing body of work within political psychology attempts to explain Brexit using a variety of approaches. Qualitative work has focused on the different category constructions, arguments, and meanings mobilised by people on both sides of the Brexit issue. For example, Andreouli et al. (2019) conceptualised Brexit through the lens of emergence, in which the "ordered universe of the political status quo has been disrupted and that something new is at play in the passage of politics" (p. 6). Their work described different styles of argumentation 
associated with 'remainers' and 'leavers' - thought and feeling - which differed crucially in their interpretation of political values and authority, and attached variable importance to affect. In a similar vein, a rhetorical analysis of focus group data with 'remainers' and 'leavers' revealed differences in the way in which these groups oriented to the ideological dilemma of nationalism, as well as the contrast between reason and bias (Andreouli \& Nicholson, 2018). Quantitative work has, for the most part, attempted to explain support for Brexit in psychological terms, including but not limited to: attitudes towards supranational governance (Peitz, Dhont, \& Seyd, 2018), collective narcissism (e.g. Golec de Zavala, Guerra, \& Simão, 2017) and concerns about immigration and political trust (Abrams \& Travaglino, 2019). The consequences of Brexit have received comparatively less support. One study linked the experience of disillusionment among 'remainers' to increased support for more extreme political positions (Maher, Igou, \& van Tilburg, 2018). The present study develops this line of work by offering insight into the way in which meta-representations are constructed, and how they are implicated in political action.

\section{The Current Study}

The current study investigated the way in which two features of a society's metarepresentational fabric - constructions of perceived political disagreement and the opinion climate were implicated in people's construals of their political participation. To examine this, I conducted semi-structured interviews with participants who voted to remain in the EU referendum in 2016, and who lived and voted in UK constituencies which represented diverse opinion climates in relation the Brexit issue. The decision to focus on the perspectives of 'remainers' was underpinned by the conceptual tools employed in the study. Both spiral of silence theory and a SRA centre the perceptions and actions of minority groups in the process of social and political change. On a national level, it seemed plausible that those who voted to 
remain in the EU would have recognised their beliefs as belonging to the minority, even if this was a slim one.

\section{Method}

\section{Participants}

Nineteen British participants ( 8 female) participated in individual interviews in July 2017, approximately one month after the 2017 general election. Participants were aged between 19 and 73 years $(M=45.84, S D=17.93)$. The majority of participants $(N=15)$ were recruited through their prior completion of an online survey three months previously, at the end of which participants had the option to provide their email address if they were interested in participating in a follow-up interview (the remaining four participants were recruited through the author's personal contacts, two of whom were personally known to the author). This survey explored similar issues to the current study, and comprised questions which measured UK residents who voted to remain's collective action intentions in the context of Brexit, their levels of European and British identification, personal attitudes towards Brexit as well as the attitudes which were attributed to the British public. Participants were also asked to provide demographic information, including details of the constituency in which they lived. I recruited a convenience sample to complete this survey via advertisement on social media $(N=1602)$.

Using the survey data, purposive sampling was adopted in order to ensure the diversity of participant's opinion climates, operationalised as remain vote share in the participant's constituency and the position of their local MP on Brexit (remain or leave). No claims are made here about the representativeness of the sample in terms of party identification or geographical region. However, a broad range of opinion climates is evident in the sample. Participants lived in constituencies with very high (72\%) to very low (36\%) 
remain vote shares, and eight participants were represented by leave-supporting MPs (see Table 1). I aimed not to discern differences between participants depending on remain vote share, but to include as diverse a range of constituencies as possible. Further participant demographic information is provided in Table 1. All participants were assigned pseudonyms for the analysis.

\section{Procedure}

Prior to the interview, participants read information about the study and provided consent and demographic information via email. Interviews took place over phone, lasted between 25 and 63 minutes $(M=41.95, S D=11.81)$, and were digitally recorded. The semistructured interview schedule addressed (1) participants' engagement in and perceptions of anti-Brexit political action; (2) their perceptions of Brexit and the current negotiations between the UK government and the EU; and (3) their views about the ways in which others in UK society (people in their local area, national politicians) perceived and understood the Brexit issue.

\section{Analysis}

The audio files were transcribed verbatim and analysed using thematic analysis (Braun \& Clarke, 2006). This method of analysis, described elsewhere as "a pragmatic approach to qualitative analysis" (Dewe \& Coyle, 2014; p. 23) is useful in terms of its theoretical and epistemological flexibility I adopted a critical realist stance here (e.g. Bhaskar, 1975; Collier, 1994; Fletcher, 2017), and followed an approach which incorporated both inductive and deductive aspects. The use of thematic analysis allowed the identification of themes which spoke to the research question, namely the relationship between perceptions of disagreement and opinion climate, and construals of anti-Brexit political action. However, as will be shown, across these themes it was also possible to discern a particular social 
representation of public opinion more broadly, which was characterised by various attributes and had further consequences for political action.

To begin the analysis, I read the transcripts numerous times in order to get an overall sense of the data. Following this, I applied a coding framework to the data in order to capture data which were relevant to the research question. There were two theoretically-derived priorities: (1) constructions of political participation and collective action (e.g. involvement, perceived efficacy, and constraints); and (2) constructions of meta-representations, in which all data pertaining to the opinions and perceptions attributed to a generalised majority (e.g. 'everybody thinks...', 'the public thinks...') were coded. Following this initial coding of the relevant data, themes were developed and labelled by grouping codes of similar meaning. Finally, the themes were reviewed in order to ensure their distinctiveness, and were then described and interpreted in a detailed analysis.

\section{Findings}

The thematic structure developed in the analysis is depicted in Table S1. Four themes were identified: (1) a broken political system; (2) no way back from Brexit; (3) reading the public; and (4) individual versus collective participation. The former two themes relate to constructions of the UK political context and, while they provide rich descriptive detail, do not allow purchase on the central research question and so will not be discussed here. The latter two themes both relate to participants' constructions of their engagement in anti-Brexit political action and the ways in which political disagreement and the opinion climate were implicated, and will now be discussed.

\section{Reading the Public}

Throughout the discussions, participants' talk about their experiences of political disagreement and their perceptions of the opinion climate elaborated a social representation 
of public opinion which was characterised by ambivalence. Public opinion was constructed as inscrutable, uninformed, and broadly supportive of Brexit. Simultaneously, while it had frustrated participants' pro-EU aspirations through the EU referendum result, its volatility necessarily left open the possibility of a future swing to a more pro-EU position. These elements of the social representation will now be discussed.

Participants frequently expressed surprise at the actions of the voting public, in relation to both the EU referendum and the results of the 2017 general election, and they reflected on the meaning of these results for public opinion generally or in relation to the type of Brexit which the public favoured. More broadly, the Brexit vote was linked to a construction of the public as either misrecognised or unrecognised: participants' expressed shock at a previously unseen public announcing its presence, or acknowledged that their beliefs about the public were in some way incorrect. This was directly linked to participants' experiences of political disagreement and their readings of the opinion climate. Participants occupied mostly homophilic social networks: almost all participants stated that, at the time of the vote, they interacted with people with whom they agreed politically. Consequently, the EU referendum brought about a process whereby the 'true' nature of the public was revealed, or, alternatively, in which previously unacknowledged segments of the public came into focus:

I: $\quad$ Um what would you say that Brexit means to you personally?

Christopher: Um eh (laughs) (pause) again it's quite a difficult, a kind of emotional, and it's hard, said by other people and by people in the US that I just don't feel that, I don't really feel (laughs) British anymore. It feels um (pause) it kind of feels like my country's been hijacked, that's how it feels to me. I know that's a ridiculous thing to say but um I just kind of feel that all the kind of values that I thought we shared, I thought I shared with my kind of fellow citizens, I know 
we disagreed on lots of issues but I thought we had certain values in common, the majority of people had certain values in common and I think that that's just been ripped asunder. It's just (pause) the fact that people, and this again was where Trump in America, the people are willing to harm themselves economically eh in order to keep a minority group down and out, literally out of the country, is uh, is I find really shocking.

(44, Yorkshire \& the Humber)

Kate: ...That's something in Scotland that I noticed a lot with that, we didn't, we didn't have any really signs 'vote leave', 'vote remain', there was not sort of the, I didn't feel like we saw the same sort of visual imagery you have when there's an election or definitely compared to the independence referendum and it was only when my parents went to Cornwall that summer, and they went 'there's loads of leave posters, there's loads of leave posters everywhere!' And this must have been a week or so before the referendum, I suddenly went 'oh my god it's like different other places'! People were, we just thought people were kinda just they're going well, this, there's not actually that much of a debate, it's already been decided, we know the answer.

(24, Scotland)

In both of these excerpts, that the Brexit vote has brought about a process of recognition or misrecognition of the public is clear. For Christopher, the public has, through the referendum, revealed its 'true' nature; the basis for national identity and solidarity has been 'ripped asunder' by an act of national self-injury fuelled by anti-immigrant sentiment. His perception of commonality with 'the majority of people' has been revealed as an illusion; his country has been 'hijacked' by a public which had been previously unnoticed, a phenomenon which he constructs as analogous to the election of President Trump in the United States. On the 
other hand, Kate's account evidences a process of recognition of the British public (the 'people'), or the parts of it which had been unacknowledged prior to the vote. A contrast is developed between the visibility and polarisation of the 2014 independence referendum campaign in Scotland, and the absence of debate ("we know the answer") and dearth of "visual imagery" of the EU referendum campaign. Related again to perceptions of the opinion climate, the recognition of this fundamentally different public is constructed here as stemming from second-hand knowledge and experience, specifically from a travel report from an area of England which eventually voted to leave. Given the homophilic networks which participants described and occupied, journalism was another means by which this process of recognition came about. The social representation of public opinion as inscrutable was thus directly related to the absence of political disagreement, or to the perception of a broader opinion climate which was consonant with one's own perspective.

Another element of the social representation of public opinion which was apparent in the discussions related to knowledge. The public was frequently characterised as ill-informed and unable to deal with complex issues, such as Brexit. This lack of political knowledge or interest among the public was constructed as a contributing factor in the EU referendum result. This social representation of public opinion as lacking in political sophistication or knowledge was also evident in participants' talk about the democratic process:

Paul: The Lib Dems, they're a remain party. The problem is their campaign, well as the election in any rate, they were campaigning for a second referendum and I, there isn't an appetite for a second referendum. There should never be a referendum ever again on anything. If this is, if what happens ends up being put to bed, um it needs parliament to actually knock it on the head. No referendums ever again.

(40, East of England) 


\begin{abstract}
$* * *$
Philip: So the unpredictability of why people vote for what they do, I suppose in a sense that helps to create an atmosphere or a view where you think well maybe this democracy is a bit random and rather than people thinking carefully about what they want and then voting for it, they actually apply their vote to what to me would be a very cavalier fashion. I mean they're entitled to, that is what democracy is but I suppose I've become slightly more conscious and hence slightly more worried about that.
\end{abstract}

(65, South East England)

Asked about the approaches of the different political parties to Brexit, and orienting here to the position of the pro-remain Liberal Democrat party to bring about a second Brexit referendum, Paul asserts that there should be "no referendums ever again", while Philip constructs the "unpredictability" of public opinion and its ill-considered nature (and the consequences of this for voting behaviour) as troubling his conceptualisation of democracy. Both accounts, implicitly and explicitly, work to construct the public as something to be managed and contained, and serve to legitimate means of political representation which emphasise representative (rather than direct) forms of decision-making, that is through parliamentary sovereignty.

The final relevant element of social representations of public opinion revealed in these discussions concerned its volatility. It was construed as changeable and fluid, though not necessarily as moving towards a more pro-EU position: "I think a lot of people have changed their mind from remain to leave" (Charlotte, 19, Wales). It was a disruptive force with a neutral valence in the data. It could have a negative (from their perspective) influence; the Brexit vote was often explained as a protest vote against the political establishment, to "give Cameron (the UK Prime Minister at the time of the EU referendum) a bloody nose" (Emily, 52, South West England). But its disruptive potential also offered hope: 
Philip: Yeah I mean the hubris that she (Prime Minister Theresa May) would get a huge majority, we'd all fall in line, we'd all be Brexiteers (Brexit supporters) and what the electorate delivered was uh a loss of majority, a loss of power, a hung parliament um and now it means parliament itself, has got more power than it was going to get out of the executive. It's astonishing that the slogan was 'take back control' and that seemed to me, take back control to the executive or the Brexiteers, not parliament, parliamentary sovereignty, which is our constitution. But now I think there is a chance, with alliances being made, that we will get a better outcome than we did before, than we would have had before, or would have had were there a May majority government.

(65, South East England)

Here, public opinion's volatility is constructed as a positive force - in the context of the UK general election of 2017, it is set up as a brake on the ambitions of political elites ("the hubris that she would get a huge majority"), which in this instance served to redirect power away from a select elite group and restore "our constitution", the natural order of things "parliamentary sovereignty". Elsewhere, public opinion, because of its volatility, was constructed as a potential source of optimism in the context of Brexit: "I think when it starts hitting people's pockets in a noticeable way, there might be another opportunity" (Nick, 29, East of England). Thus, the social representation of public opinion was characterised by ambivalence and contradictions, and accompanied by similar ambiguity in terms of participants' construals of the possibility of overturning Brexit.

\section{Querying the Collective}

Participants' situated their political participation and engagement within 'a broken political system' in the UK. Politicians were characterised as untrustworthy, unresponsive, 
and broadly committed to Brexit. Consequently, as individuals supportive of remaining in the EU, there was a sense of political homelessness as they reported lack of identification with political parties. Furthermore, a discourse of 'no way back from Brexit' was worked up in the discussions; public opinion was construed as broadly supportive of Brexit and the fractious political atmosphere closed off possibilities for debate.

Within this context, participants' talk about their engagement in anti-Brexit political action and its efficacy suggested a tension between 'individual versus collective participation'. The possibility and efficacy of collective action in relation to Brexit was queried and so, for some participants, political action was primarily constructed as occurring and being of value at the individual level. Individual political actions which participants advocated or reported engaging in were often internet-mediated (e.g. signing online petitions, posting on social media), or involved communicating with relevant others to make an individual's opinion heard (e.g. speaking to opinion pollsters, writing to the press). Informal and local campaigning, rather than formal and national, was emphasised: "I was trying to inform people you know on social media and talking to them about the reasons why we should remain and feel because they're so affected by right-wing media, they just didn't listen" (Sarah, 35, East of England). This favouring of individual anti-Brexit political acts was also related to the fractiousness of current political discourse:

James: I'm a member of Open Britain. I tweet, I go on Facebook. I'm not sure I want to get involved through political parties. It's uh, it's not great, I mean my neighbour went to a Labour party meeting with all good intentions to take part. It was awful, it was a slanging match between two old war horses in the Labour party, and he came away thinking 'I don't want to do this'. So it's a bit like that at local level here.

(71, North West England) 
Martha: I mean I tried to influence anyone I talked to but I didn't spend time down at the pub um because I thought that would just, you know end up with me being shouted at.

(63, East of England)

In both of these excerpts, perceptions of political disagreement and the opinion climate are clearly implicated in participants' accounts of their political participation. Awareness of a polarised opinion climate is related in both to a conscious decision to moderate one's political engagement.

Furthermore, participants talk about the effects and outcomes of anti-Brexit political action reflected this tension between 'individual versus collective participation'. While some participants reported being involved in cross-party pro-EU organisations following the referendum, their effectiveness was questioned: "I joined a plethora of, there's More United, organisations like that that sprung up in the immediate aftermath uh but they don't seem to have gone anywhere" (Christopher, 44, Yorkshire \& the Humber). The government's response to previous pro-EU demonstrations appeared to have a negative effect on participants' judgements of the efficacy of anti-Brexit political action:

David: I don't see any clear-cut way of um making an individual voice heard and even and it's been quite disheartening to see lots of large campaigns, large protests and very vocal um groups um, especially given the size of the remain vote, and the fact that it's swatted down almost instantly. It looks like the current parliament will be holding fast on its position of leaving the EU, for fear of offending the 52 per cent that voted leave.

(30, Greater London)

Evident here and throughout the discussions was a querying of the efficacy of anti-Brexit collective action. Interesting here, however, is the individualised construction of efficacy 
which is mobilised by David ("I don't see any clear-cut way of um making an individual voice heard"). Relatedly, elsewhere in the discussions, the efficacy of anti-Brexit political action was rehabilitated with recourse to an emphasis on the benefits to the individual of these actions, by helping to clarify one's thoughts or simply to make one's view known: "I really did it for the self-satisfaction of recording my view and making my MP you know aware of it" (Philip, 65, South East England). Thus, concerns about the efficacy of anti-Brexit political action at the collective level were at some points assuaged via a prioritisation of individual benefits.

\section{Discussion}

Meta-representations were related to participants' construals of engagement in antiBrexit political action. A social representation of public opinion characterised by ambivalence was evident; by participating and contributing to a discourse which emphasised the inevitability of Brexit, it closed down the possibility of resistance to Brexit, but as a volatile, inscrutable, and disruptive force, it left open the possibility of its future movement towards a more pro-EU position. Alongside this representation of public opinion, constructions of a polarised and dysfunctional political system worked to sustain a mode of political engagement which prioritised and viewed as efficacious individual rather than collective anti-Brexit action.

Perceptions of political disagreement and of the opinion climate, in addition to constructions of the broader political and discursive context, worked in the data to legitimate forms of anti-Brexit political participation which prioritised individual rather than collective forms of participation. Previous (quantitative) research exploring the impact of the social normative context on political behaviour and expression has tended to focus on willingness to engage in one particular political act, for example to speak with a journalist about a political 
issue (e.g. Louis et al., 2010) However, this analysis suggests that people may prefer different modes of political participation depending on the opinion climate which they occupy and the way in which they construe it. Thus, by focusing on specific and individual political actions, previous empirical work may have not picked up on this complexity. Future empirical studies, including those which draw upon spiral of silence theory, should therefore investigate the impact of perceptions of political disagreement and opinion climate on political behaviours and expression with reference to a wider range of political actions.

Participants' talk about their engagement in political processes reflected a sense of disillusionment in relation to the Brexit issue. None of the political parties were constructed by participants as fully representing their views in relation to this issue. Given that previous empirical work has specified collective or social identity as a critical determinant of collective action (e.g. van Zomeren, Postmes, \& Spears, 2008; Simon et al., 1998), it remains unclear to what extent effective anti-Brexit collective action could effectively be mobilised without the presence of a unifying collective identity. Additionally, the potential of these individual political acts to somehow forge a sense of collective identity, which might then translate into collective action, should be investigated empirically using longitudinal methods.

As in previous work (Maher et al., 2018), the experience of disillusionment was linked here to a moderation of political participation, specifically a prioritisation of individual expressions of political opinion and atomised anti-Brexit actions, however unlike the previous work it did not appear to lead to support for more extreme political views or actions. Leading from this, it is an open question in the data as to whether this movement towards individual rather than collective anti-Brexit action, precipitated by perceptions of public opinion and the political context, affords the public with a greater voice in the Brexit debate. Two interpretations are possible here. Firstly, that disenchantment with party politics is 
experienced as demobilising in the absence of formal political structures and there is consequently a reduced capacity for influence. Conversely, it could be interpreted that lack of alignment with party structures could, via the muted influence of elite cues, lead to a higher capacity for social influence. These explanations are worth further theoretical and empirical investigation.

Participants frequently judged the public to be ill-informed politically or not in possession of the resources necessary for dealing with complex issues. Simultaneously, public opinion was constructed as volatile and as a disruptive force, which was necessarily neutral in valence. It had frustrated participants' wishes on the $23^{\text {rd }}$ June 2016 , but equally it had declined to extend its mandate to the Conservative party to pursue a Brexit of its sole determination in the 2017 general election. Thus, public opinion was constructed as something to be contained and managed, as well as a possible brake on Brexit in the future.

The social representation of public opinion as something to be contained and managed implicitly endorsed moves away from more direct forms of democracy, to calls to strengthen the functioning of representative, parliamentary democracy, which was constructed as the 'natural order' of the UK political system. The findings here suggest that emergent forms such as Brexit (Andreouli et al., 2019) may reposition the legitimacy of political authority via a refiguring of the status afforded to the public and its opinion. The lack of status granted to public opinion here may be related to the different styles of argumentation associated with 'remainers' and 'leavers' - thought and feeling (Andreouli et al., 2019), or to their difference stances vis a vis the nationalism dilemma and the reason/bias distinction (Andreouli \& Nicholson, 2018). Distrust of the public makes sense when the style of that public's engagement with political issues is unintelligible. 
This dynamic interplay between constructions of public opinion, construals of political authority, and support for specific forms of democratic governance can be illustrated with two examples. Firstly, the 'People's Vote' campaign for a second, confirmatory referendum, has been salient to varying extents since the referendum result was announced. Secondly, Prime Minister Johnson's August 2019 proposal to suspend parliament for a period of five weeks prior to the date of the UK's mooted date of departure. Both of these examples have been construed as a means of enacting public opinion and a subversion of it. Thus, depending on which social representation of public opinion is mobilised, authority or ignominy is conferred on political elites, and decisions are either democratic outrages, or eminently sensible.

The interplay between these constructs warrants further theoretical and empirical examination to increase understanding of the direction of future democratic support, as well as for other forms of governance, ranging from more participatory and inclusive forms of democracy (e.g. citizen assemblies) to support for policies which might indicate a shift towards autocracy (e.g. suppression of the media, restrictions on civil liberties etc.). Recent events in the UK, United States, Brazil, and elsewhere, underscore the necessity of not taking democratic support for granted, and a political psychology which recognises this is required. The findings of this study suggest the SRA as a suitable candidate for this task.

The social representation of public opinion as volatile afforded a sense of 'narrative plausibility' (Mahendran et al., 2015) to the story of the UK's continued engagement with the EU. Previous work exploring the impact of public opinion on political behaviour and expression has tended to emphasise its negative effects, its potential to silence or close down possibilities for action (e.g. Bassili, 2003; Noelle-Neumann, 1974). However, in line with previous work (Louis et al., 2010; O’Dwyer et al., 2016), these findings are suggestive of the empowering potential of perceptions of political disagreement and the prevailing opinion 
climate. A SRA, by emphasising the constructed, context-dependent, and changeable nature of these aspects of the meta-representational fabric highlights this agentic potential.

That the social representation of public opinion is characterised by tensions and contradictions, is, I would argue, grounded in the ambivalence which characterises lay thinking about the nature of the masses themselves. Salient here is a narrative which construes the collective as irrational and emotional, as a threat to the autonomy, freedom, and rationality of the individual (Greenwood, 2004). These values are foundational for political liberalism, a belief system which, arguably, has buttressed the social psychology's historic individualistic focus (Farr, 1996; Klein, 2009). This interpretation sheds light on the potential contribution of a SRA to the understanding of dynamic democratic processes via: (1) making salient the ideological baggage which meta-representations carry; and (2) calling our attention to their historical and contextual contingency.

There are a number of limitations to the current study. Firstly, participants identified with left-wing or centre-left parties. None identified with the Conservative party, even though Conservatives voters clearly did vote to remain in the EU, albeit perhaps for different reasons to the justifications offered by the participants here. It may have been the case that such potential participants were more reluctant to participate in this research. Given that the focus of this study was the way in which perceived political disagreement and opinion climate were constructed and implicated in people's construals of their engagement in anti-Brexit political action, this may not be too problematic. However future research on this issue should do more to include 'remainers' who do not identify with centre-left/left-wing political parties.

Secondly, there may be apprehension about the validity of any claims which can be drawn from these data, or about the robustness of the analysis. Any claims to represent in an objective way the perspectives of these participants would be counter to the objectives of 
qualitative research, which foregrounds participants' subjective understandings and meanings, and recognises the integral role of the researcher in the research process. However, steps were taken to ensure that the research fulfilled criteria essential for rigorous and reflexive qualitative research (e.g. Yardley, 2000), for example through writing memos and recording impressions of the interviews.

In summary, and consonant with previous work in social psychology and political science, this study shows that perceptions of political disagreement and the opinion climate are central to people's understandings of their engagement in political processes. However, it also suggests that the opinion climate might alter the preferred mode of political participation. Furthermore, the representation of public opinion evident here highlights the necessity of investigating the valence which is attached to the opinion climate, and of acknowledging that this may be ambivalent and contradictory, with concomitant consequences for political behaviour, as well as support for different types of democratic governance. Taken together, these findings emphasise the importance of considering the relationship between metarepresentations and political action, but make the case for conceptualising this relationship as shifting and dialogical. Social norms are not facts 'out there' which people incorporate into their decision-making in an unthinking way - they are constructed, interpreted, engaged with, and perhaps, resisted. 
Table 1

Demographic and political characteristics of participants and constituency information

\begin{tabular}{|c|c|c|c|c|c|c|c|c|}
\hline Name & Age & Gender & $\begin{array}{l}\text { Employment } \\
\text { Status }\end{array}$ & $\begin{array}{l}\text { Political } \\
\text { Affiliation }^{\mathrm{b}}\end{array}$ & UK Region & $\begin{array}{l}\text { Remain } \\
\text { Vote } \%\end{array}$ & $\begin{array}{l}\text { Current MP } \\
\text { Party }\end{array}$ & $\begin{array}{l}\text { Current MP } \\
\text { Position }\end{array}$ \\
\hline $\mathrm{Amy}^{\mathrm{a}}$ & 28 & Female & Employed & Lab & Greater London & 58.1 & Con & Leave \\
\hline Andrew & 55 & Male & Employed & None & Greater London & 77.6 & $\mathrm{Lab}$ & Leave \\
\hline Charlotte $^{\mathrm{a}}$ & 19 & Female & Student & $\mathrm{Lab}$ & Wales & 50.4 & Con & Leave \\
\hline Christopher & 44 & Male & Employed & None & Yorkshire \& the Humber & 36.3 & $\mathrm{Lab}$ & Remain \\
\hline Colin & 73 & Male & Retired & $\mathrm{Lab}$ & East of England & 72.4 & Lab & Remain \\
\hline David $^{a}$ & 30 & Male & Employed & None & Greater London & 51.6 & Con & Leave \\
\hline Emily & 52 & Female & Unemployed & GP & South West England & 53.0 & Con & Remain \\
\hline Geraldine & 49 & Female & Student & Lab & Northern Ireland & 50.4 & DUP & Leave \\
\hline James & 71 & Male & Retired & Lab & North West England & 41.5 & $\mathrm{Lab}$ & Remain \\
\hline Julie & 40 & Female & Employed & None & East of England & 38.1 & $\mathrm{Lab}$ & Remain $^{\mathrm{d}}$ \\
\hline Kate & 24 & Female & Employed & GP & Scotland & 61.9 & SNP & Remain \\
\hline Martha & 63 & Female & Unemployed & $\mathrm{Lab}$ & East of England & 45.1 & Con & Leave \\
\hline Nick & 29 & Male & Employed & Lab & East of England & 62.6 & Con & Leave \\
\hline Paul & 40 & Male & Employed & None & East of England & 36.8 & Con & Remain \\
\hline Peter $^{\mathrm{a}}$ & 65 & Male & Retired & $\mathrm{Lab}$ & South West England & 53.0 & Con & Remain \\
\hline Philip & 65 & Male & Retired & None & South East England & 46.0 & Con & Remain \\
\hline Sam & 22 & Male & Employed & None & Greater London & 75.4 & Lab & Remain \\
\hline Sandra & 67 & Female & Employed & $\mathrm{LD}$ & Scotland & 75.0 & SNP & Remain \\
\hline Sarah & 35 & Female & Employed & $\mathrm{Lab}$ & South East England & 37.6 & Con & Leave \\
\hline
\end{tabular}

${ }^{\mathrm{a}}$ These participants were recruited through personal contacts of the researcher.

${ }^{\mathrm{b}}$ Lab $=$ Labour Party, Con $=$ Conservatives, DUP $=$ Democratic Unionist Party, SNP $=$ Scottish National Party, GP $=$ Green Party, Lib Dem $=$ Liberal Democrats.

${ }^{\mathrm{c}}$ Aside from this constituency, all participants were represented by an MP of the same party at the time of the referendum and after the 2016 general election. This constituency switched from Conservative to Labour in 2016.

${ }^{\mathrm{d}}$ In this constituency, the Conservative MP at the time of the referendum vote supported the leave campaign. 


\section{References}

Abrams, D., \& Travaglino, G. A. (2018). Immigration, political trust, and BrexitTesting an aversion amplification hypothesis. British Journal of Social Psychology, 57, 310326.

Andreouli, E., Kaposi, D., \& Stenner, P. (2019). Brexit and emergent politics: In search of a social psychology. Journal of Community \& Applied Social Psychology, 29, 6-17.

Andreouli, E., \& Nicholson, C. (2018). Brexit and everyday politics: an analysis of focus-group data on the EU referendum. Political Psychology, 39, 1323-1338.

Bassili, J. N. (2003). The minority slowness effect: subtle inhibitions in the expression of views not shared by others. Journal of Personality and Social Psychology, 84, 261-276.

Bhaskar, R. (1975). A realist theory of science. London: Verso.

Bodor, T. (2012). The issue of timing and opinion congruity in spiral of silence research: why does research suggest limited empirical support for the theory? International Journal of Public Opinion Research, 24, 269-286.

Braun, V., \& Clarke, V. (2006). Using thematic analysis in psychology. Qualitative Research in Psychology, 3, 77-101.

Collier, A. (1994). Critical realism: An introduction to Roy Bhaskar's philosophy. London; New York: Verso.

Dewe, M., \& Coyle, A. (2014). Reflections on a study of responses to research on smoking: A pragmatic, pluralist variation on a qualitative psychological theme. Review of Social Studies, 1, 21-36. 
Elcheroth, G., Doise, W., \& Reicher, S. (2011). On the knowledge of politics and the politics of knowledge: How a social representations approach helps us rethink the subject of political psychology. Political Psychology, 32, 729-758.

Farr, R. M. (1996). The roots of modern social psychology, 1872-1954. London: Wiley.

Fletcher, A. J. (2017). Applying critical realism in qualitative research: methodology meets method. International Journal of Social Research Methodology, 20, 181-194.

Glynn, C. J., Hayes, A. F., \& Shanahan, J. (1997). Perceived support for one's opinions and willingness to speak out: A meta-analysis of survey studies on the" spiral of silence". Public Opinion Quarterly, 61, 452-463.

Golec de Zavala, A., Guerra, R., \& Simão, C. (2017). The relationship between the Brexit vote and individual predictors of prejudice: Collective narcissism, right wing authoritarianism, social dominance orientation. Frontiers in Psychology, 8, 2023.

Goncalves-Portelinha, I., Staerklé, C., \& Elcheroth, G. (2017). Political beliefs and political behaviour. In C. Howarth \& E. Andreouli (Eds.), The social psychology of everyday politics (pp. 222-236). London: Routledge.

Greenwood, J. D. (2004). What happened to the "social" in social psychology? Journal for the Theory of Social Behaviour, 34, 19-34.

Howarth, C. (2006). A social representation is not a quiet thing: Exploring the critical potential of social representations theory. British Journal of Social Psychology, 45, 65-86.

Jovchelovitch, S. (1995). Social representations in and of the public sphere: Towards a theoretical articulation. Journal for the Theory of Social Behaviour, 25, 81-102. 
Klein, O. (2009). From utopia to dystopia: Levels of explanation and the politics of social psychology. Psychologica Belgica, 49, 85-100

Louis, W. R., Duck, J. M., Terry, D. J., \& Lalonde, R. N. (2010). Speaking out on immigration policy in Australia: Identity threat and the interplay of own opinion and public opinion. Journal of Social Issues, 66, 653-672.

Mahendran, K. (2018). From polarized we/they public opinion on European integration towards social representations of public dialogue. Political Psychology, 39, 13391355.

Mahendran, K. (2017). Public narratives on human mobility: Countering technocratic and humanitarian refugee narratives with a "one-world" solidarity narrative. Journal of Community \& Applied Social Psychology, 27, 147-157.

Mahendran, K., Jackson, I., \& Kapoor, A. (2015). Dialogical citizen in the European public sphere. In U. Korkut, K. Mahendran, G. Bucken-Knapp, \& R. Henry-Cox (Eds.), Discursive governance in politics, policy and public sphere (pp. 147-62). New York, NY: Palgrave Macmillan.

Maher, P. J., Igou, E. R., \& van Tilburg, W. A. (2018). Brexit, Trump, and the polarizing effect of disillusionment. Social Psychological and Personality Science, 9, 205 213.

Matthes, J. (2012). Do hostile opinion environments harm political participation? The moderating role of generalized social trust. International Journal of Public Opinion Research, 25, 23-42. 
Matthes, J., Rios Morrison, K., \& Schemer, C. (2010). A spiral of silence for some: Attitude certainty and the expression of political minority opinions. Communication Research, 37, 774-800.

McClurg, S. D. (2006). Political disagreement in context: The conditional effect of neighborhood context, disagreement and political talk on electoral participation. Political Behavior, 28, 349-366.

Moscovici, S. (1976). Psychoanalysis: Its image and its public. Cambridge, UK: Polity Press. (Original work published in 1961.)

Mutz, D. (2002). Cross cutting social networks: Testing democratic theory in practice. American Political Science Review, 96, 111-126.

Nir, L. (2011). Disagreement and opposition in social networks: Does disagreement discourage turnout? Political Studies, 59, 674-692.

Noelle-Neumann, E. (1974). The spiral of silence: A theory of public opinion. Journal of Communication, 24, 43-51.

Noelle-Neumann, E. (1984). The spiral of silence: Public opinion - our social skin. Chicago: University of Chicago Press.

Noelle-Neumann, E., \& Petersen, T. (2004). The spiral of silence and the social nature of man. In L. L. Kaid (Ed.), Handbook of Political Communication Research (pp. 339-357). Mahwah: Lawrence Erlbaum.

O'Dwyer, E., Lyons, E. \& Cohrs, J. C. (2016). How Irish citizens negotiate foreign policy: A social representations approach to neutrality. Political Psychology, 37, 165-181. 
Peitz, L., Dhont, K., \& Seyd, B. (2018). The psychology of supranationalism: Its ideological correlates and implications for EU attitudes and post-Brexit preferences. Political Psychology, 39, 1305-1322.

Portelinha, I., \& Elcheroth, G. (2016). From marginal to mainstream: The role of perceived social norms in the rise of a far-right movement. European Journal of Social Psychology, 46, 661-671.

Scheufle, D. A., \& Moy, P. (2000). Twenty-five years of the spiral of silence: A conceptual review and empirical outlook. International Journal of Public Opinion Research, $12,3-28$

Simon, B., Loewy, M., Stürmer, S., Weber, U., Freytag, P., Habig, C., ... \& Spahlinger, P. (1998). Collective identification and social movement participation. Journal of Personality and Social psychology, 74, 646.

Staerklé, C., Clémence, A., \& Spini, D. (2011). Social representations: A normative and dynamic intergroup approach. Political Psychology, 32, 759-768.

Van Zomeren, M., Postmes, T., \& Spears, R. (2008). Toward an integrative social identity model of collective action: a quantitative research synthesis of three sociopsychological perspectives. Psychological Bulletin, 134, 504-35.

Vraga, E. K., Thorson, K., Kligler-Vilenchik, N., \& Gee, E. (2015). How individual sensitivities to disagreement shape youth political expression on Facebook. Computers in Human Behavior, 45, 281-289.

Yardley, L. (2000). Dilemmas in qualitative health research. Psychology \& Health, $15,215-228$. 


\section{Table S1}

Level 1-3 themes developed in the thematic analysis

\begin{tabular}{|c|c|c|}
\hline Codes (Level 1) & Subthemes (Level 2) & Themes (Level 3) \\
\hline $\begin{array}{ll}\text { - } & \text { Identification with political parties } \\
\text { - } & \text { A political vacuum } \\
\text { - } & \text { Lack of political opposition } \\
\text { - } & \text { Inadequate political leaders }\end{array}$ & a) No one to vote for & 1. A Broken Political System \\
\hline $\begin{array}{l}\text { - } \quad \text { Lack of accountability of politicians } \\
\text { - } \quad \text { Lack of trust in politicians } \\
\text { - } \quad \text { Politicians aren't listening } \\
\text { - } \quad \text { Safe seats and powerlessness }\end{array}$ & $\begin{array}{l}\text { b) Politicians cannot } \\
\text { be trusted to be } \\
\text { responsive }\end{array}$ & $\begin{array}{l}\text { liberal Labour-ish, um but no, now, I } \\
\text { don't know where I am either". } \\
\text { (Julie, 40, East of England) }\end{array}$ \\
\hline $\begin{array}{ll}\text { - } & \text { Fractious political discourse } \\
\text { - } & \text { Can't reason with Leavers } \\
\text { - } & \text { Will of the people must be respected } \\
\text { - } & \text { Impossibility of a second referendum }\end{array}$ & a) Communication & 2. No Way Back From Brexit \\
\hline $\begin{array}{l}\text { - } \quad \text { No public demand for a second referendum } \\
\text { - } \quad \text { People have accepted the referendum result } \\
\text { - } \quad \text { Public opinion is behind Brexit }\end{array}$ & $\begin{array}{l}\text { b) Pro-Brexit public } \\
\text { opinion }\end{array}$ & $\begin{array}{l}\text { "I'm not sure there's much demand } \\
\text { from the country for a second } \\
\text { referendum". } \\
\text { (Christopher, } 44 \text {, Yorkshire \& the } \\
\text { Humber) }\end{array}$ \\
\hline
\end{tabular}

- Direct democracy doesn’t work

- Distrust of the public

- The public can disrupt the plans of politicians

- The public was misidentified

- Acknowledging a different public

- The meaning of votes for public opinion

- Social media causes people to be less politically informed

- The public is ill-equipped to deal with complex issues

- Not that engaged in politics

- The public is overwhelmed by Brexit

- The public memory

- Brexit has politicised the public

- Change in public opinion

- Public may realise Brexit is a mistake

- Public opinion is fractured

- The mood of the public

- The public is bored of Brexit

- Communicating with opinion pollsters

- Contacting MP about Brexit

- Informal campaigning for remain

- Attending pro-EU demonstrations

- Signing online petitions

- Using social media to express political views

- Voting tactically

- Writing letters to the press for the remain campaign

- Individual benefits of participation

- Easier to influence things locally

- Lack of efficacy of political protest

- No point being active in remain areas a) Disruptive force

b) Inscrutable

c) Knowledge

\section{Reading the Public}

"So the unpredictability of why people vote for what they do...you think well maybe this democracy is a bit random..."

(Philip, 65, South East England)

d) Volatility

“...people don't read the news, they read headlines".

(Martha, 63, East of England)

\section{a) Forms of political 4. Individual versus Collective participation \\ Participation}

"I tweet, I go on Facebook. I'm not sure I want to get involved through political parties. ... It was a slanging match between two old war horses in the Labour party, and he came away thinking 'I don't want to do this'."

(James, 71, North West England) 